\title{
DELEUZE E CHAUI: LEITURAS PARALELAS SOBRE A ÉTICA DE ESPINOSA
}

Bárbara Lucchesi Ramacciotti*

\begin{abstract}
Resumo: Neste artigo pretendemos verificar em que medida as leituras de Deleuze e de Chaui nos ajudam a compreender a Ética de Espinosa como uma inovadora filosofia prática ou filosofia da práxis. O forte nexo entre teoria e prática tem sido enfraquecido por muitas leituras que defendem a tese do "paralelismo espinosano", pois atribuem um privilégio do atributo pensamento em relação à extensão, isto implicaria em um privilégio da teoria em relação à prática e à experiência. As leituras de Deleuze e de Chaui, ao contrário, sublinham que a originalidade das teses teóricas da Ética reside em sua necessária aplicação prática, portanto na inseparabilidade entre teoria e prática, pensamento e extensão, mente e corpo, tipos de conhecimento e modos de vida. Ambos propõem outra interpretação da tese nuclear do paralelismo na filosofia de Espinosa. Desdobramos a pesquisa em três tópicos: 1) leitura de Deleuze: Ética enquanto filosofia prática; 2) problema do paralelismo: as diferentes leituras; 3) leitura de Chaui: Ética enquanto filosofia da liberdade.
\end{abstract}

Palavras-chave: Espinosa. Ética. Deleuze. Chaui. Paralelismo. Filosofia Prática.

\section{Introdução}

\section{Leitura de Deleuze: Ética enquanto Filosofia Prática}

Deleuze em Spinosa et la Philosophie Prátique ${ }^{1}$ afirma que a Ética de Espinosa apresenta um novo modelo de filosofia prática, posto que no lugar de uma moral apresenta as bases de uma etologia, isto é, de uma ciência do comportamento humano, desdobrada através da teoria dos afetos e da concepção dinâmica e cinética do corpo como ser composto de múltiplos indivíduos que estão em relação de afetar e ser afetado. $^{2}$

A Ética de Espinosa não tem nada a ver com uma moral, ele a concebe como uma etologia, isto é, como uma composição das velocidades e das lentidões, dos poderes de afetar e de ser afetado nesse plano de imanência. (Deleuze 9, p.130).

Deleuze $(9$, p.23) observa que, para desenvolver na Ética uma nova concepção de filosofia prática, Espinosa rompe com a metafísica da transcendência, com o dualismo substancial cartesiano e com o moralismo vigente na filosofia moral até o

\footnotetext{
* Profa. UMC. Trabalho apresentado no Colóquio Internacional: Republicanismo e Democracia, em homenagem à prof ${ }^{a}$ Marilena Chaui, realizado na USP em 10 e 11 de novembro de 2011.
} 
século XVII, pois apresenta três grandes inovações, que são as razões pelas quais o filósofo holandês foi acusado ainda vivo de "materialismo, imoralismo e ateísmo".

Primeira inovação: Espinosa é acusado de materialismo porque desvaloriza a "consciência" como objeto central da filosofia e apresenta o corpo como um novo modelo filosófico, posição que pode ser resumida na questão "o que pode um corpo?”(Cf. escólio da proposição EII, P2). ${ }^{3} \mathrm{Na}$ Parte II da Ética, sabemos que Espinosa demonstra sua teoria da mente (mens) como ideia do corpo (proposição 11 e 12) e afirma que para saber o que é e o que pode a mente é preciso conhecer o objeto que a constitui, a saber: o corpo (EII, P13, escólio). Espinosa estabelece uma enorme ruptura com a tradição, pois além de partir da física do corpo humano para explicar o que é a mente, recusa a cisão cartesiana entre mente e corpo e rejeita todas as teorias que estabelecem a hierarquia do inteligível sobre o sensível. Isto que Deleuze identifica como a desvalorização da consciência e novo modelo do corpo:

Espinosa propõe aos filósofos um novo modelo: o corpo. Propõe instituir o corpo como modelo: 'Não sabemos o que pode o corpo'. Esta declaração de ignorância é uma provocação: falamos da consciência e de seus decretos, da vontade e de seus efeitos, dos mil meios de mover o corpo, de dominar o corpo e as paixões. (Deleuze 9, p.23)

Segunda inovação: Espinosa é acusado de imoralismo, pois desarticula as oposições metafísicas dos valores, sobretudo, entre bem e mal, além de apresentar uma tipologia dos "modos de existência imanentes", ou dos modos de vida e das maneiras de viver dos indivíduos singulares em termos da variação da potência dos afetos a partir da diferença qualitativa bom/mau. A Parte IV trata da servidão humana ou da força dos afetos, no Prefácio Espinosa esclarece que seu objetivo reside em demonstrar que as noções de bem e mal, assim como de perfeição e imperfeição, não são coisas em si mesmas, mas modos de pensar, que devem ser compreendidos como aquilo que é bom ou mau (ruim) em termos do que é útil e não útil ao aumento da potência da mente e do corpo humanos.

A Ética enquanto uma tipologia dos modos de existência imanentes substitui a Moral, a qual relaciona sempre a existência a valores transcendentes. A moral é o julgamento de Deus, o sistema de julgamento. Mas a Ética desarticula o sistema de julgamento. A oposição dos valores (Bem/Mal) é substituída pela diferença qualitativa dos modos de existência (bom/mau). (Deleuze 9, p. 29)

Terceira inovação: Espinosa é acusado de ateísmo porque desvaloriza as paixões tristes por serem signo de impotência e apresenta a alegria como signo de potência e 
virtude, com isso, faz da Ética uma filosofia prática da liberdade, da felicidade e do amor intelectual a Deus (beatitude). Deleuze refere-se à Parte III que apresenta a ciência espinosana dos afetos, a qual parte da definição dos três afetos primários: o desejo (conatus), a alegria e a tristeza (escólio da proposição 11). A alegria é definida como uma paixão pela qual a mente passa a uma perfeição maior, o que implica no aumento da realidade ou da potência, já a tristeza significa o contrário, ou seja, a passagem a uma perfeição menor e a diminuição da realidade ou impotência da mente e do corpo. $\mathrm{Na}$ Parte V, Espinosa apresenta sua teoria da liberdade como potência do intelecto e a tese da beatitude ou da suma felicidade (escólio proposição EII, 49 e Prefácio EV) como amor intelectual a Deus (Proposição EV, 33).

\begin{abstract}
A Ética é necessariamente uma ética da alegria: somente a alegria é válida, só a alegria permanece e nos aproxima da ação e da beatitude da ação. A paixão triste é sempre impotência. Este será o tríplice problema prático da Ética: $1^{\circ}$. como alcançar um máximo de paixões alegres (quando nosso lugar na Natureza parece condenar-nos aos maus encontros e à tristeza) $2^{\circ}$. como conseguir formar ideias adequadas (quando a nossa condição natural parece condenar-nos a ter de nosso corpo, de nossa mente e das outras coisas apenas ideias inadequadas); $3^{\circ}$. como chegar a ser consciente de si, de Deus e das coisas (quando a nossa consciência parece ser inseparável da ilusão). (Deleuze 9, p.34)
\end{abstract}

Essas grandes inovações da Ética espinosana apontas acima são tributárias de um duplo movimento: pois a demonstração das teses teóricas não pode ser separada das teses práticas. $\mathrm{O}$ nexo entre a teoria e a prática traduz-se nas três recusas mencionadas acima: 1) na recusa da consciência em favor do pensamento e do novo modelo do corpo; 2) na recusa dos valores transcendentes de bem e mal em favor da diferença qualitativa bom/mau em termos de variação da potência/impotência dos afetos; 3) na desvalorização das paixões tristes em favor da ética da alegria e da liberdade.

No livro Spinoza et le Problème de l' Expression, publicado em 1968, Deleuze já havia apresentado sua leitura original da teoria da expressividade da substância única (primeira parte: as tríades da substância) e da tese do paralelismo entre o atributo pensamento e o atributo extensão (segunda parte: o paralelismo e a imanência). Logo, só é possível compreender a Ética como ciência do comportamento ou como "tipologia dos modos imanentes da existência" em substituição à moral tendo por referência a ontologia da substância única e imanente.

Sabemos que na Parte I da Ética, Espinosa demonstra que só existe uma substância única que é causa de si e em si (EI, P1-7) e que todas as coisas existentes são 
produto desta causa eficiente (EI, P25). A substância única é também denominada Deus (EI, P11, P14). Contudo, o Deus de Espinosa é este que "age exclusivamente pelas leis de sua natureza" (EI, P17), sendo o mesmo que as leis da própria natureza. Só há uma substância, porque não pode existir "na natureza das coisas, duas ou mais substâncias de mesma natureza" (EI, P5) e porque "uma substância não pode ser produzida por outra substância” (EI, P6). Já que a substância infinita (EI, P13) e eterna (EI, P19) é a única causa de si e em si, logo ela opera como causa livre (EI, P17), imanente (EI, P18), eficiente (EI, P25) e necessária (EI, P29) de todas as coisas, sendo expressa em infinitos atributos infinitos (EI, P11) e em infinitos modos: "Ora, nada é dado afora substâncias e modos", afirma Espinosa (Cf. EI, P15 dem.).

Com a teoria da expressividade da substância única e imanente, Espinosa além de romper com a tradição da metafísica da transcendência, critica, em particular, o dualismo substancial cartesiano entre res cogitans e res extensa. Deleuze parte da distinção exposta por Espinosa entre substância transcendente e substância imanente para propor a diferença entre isto que denomina "plano de imanência" e "plano de transcendência". O plano de imanência remete para o "plano modal", no qual se encontram todos os corpos singulares, que existem em ato. $\mathrm{O}$ plano de imanência dos modos nada mais é que a expressão da substância única e imanente ou da "única Natureza". Já o plano de transcendência remete para uma instância teleológica, ou como um poder incondicionado, que determina ou condiciona a finalidade de toda existência (Cf. Deleuze 9, p.126). Neste viés, Deleuze sublinha a originalidade da concepção espinosana de teoria, pois a ontologia da substância única não é uma teoria no sentido tradicional que explica a existência de todas as coisas, trata-se mais de uma teoriaprática já que a compreensão de um modo de vida ou de uma maneira de viver implica a transformação das paixões tristes e impotentes em afetos alegres e potentes:

Esse plano de imanência ou de consistência não é um plano no sentido de desígnio no espírito, projeto, programa, é um plano no sentido geométrico, seção, interseção, diagrama. Então, estar no meio de Espinosa é estar nesse plano modal, ou melhor, instalar-se nesse plano; o que implica um modo de vida, uma maneira de viver. Em que consiste esse plano e como construí-lo? (Deleuze 9, p.126).

Portanto, a Ética só pode ser pensada em termos de uma filosofia da práxis que não separa teoria e prática, pois todo pensamento, ideia e teoria tem por objeto algum fenômeno, há uma conexão necessária entre as ideias e as coisas. Isto não significa que o conhecimento seja sempre verdadeiro, ao contrário, em geral, as ideias produzidas 
pela mente são inadequadas, incompletas, confusas, ou seja, são ideias imaginativas, como demonstrado na Parte II. A conexão necessária entre as ideias e as coisas é estabelecida pela célebre proposição 7, EII: “A ordem e a conexão das ideias é a mesma que a ordem e a conexão das coisas"; que é desdobrada a partir da teoria dos afetos (Parte III) e retomada na Parte V para demonstrar que a mesma maneira que se ordenam e conectam os pensamento e as ideias das coisas na mente, também se ordenam e conectam as afeções dos corpos singulares e nos modos de vida (P1, EV).

Nestes termos, Deleuze observa que a "vida não é para Espinosa uma ideia, uma questão de teoria". "A vida é uma mesma maneira de ser, um mesmo modo eterno em todos os seus atributos. E é somente deste ponto de vista que o método geométrico assume todo o seu sentido" (Deleuze 9, p. 19). O método geométrico deixa de ser um método de exposição intelectual para tornar-se, com Espinosa, um método de experimentação da inseparabilidade entre teoria e prática. A conexão teoria-prática é fundamentada pela teoria da expressividade da substância única, sobretudo pela tese do "paralelismo" entre os atributos pensamento e a extensão: "uma das teses teóricas mais célebres de Espinosa é conhecida pelo nome de paralelismo: ela não consiste apenas em negar qualquer ligação de causalidade real entre o espírito e o corpo, mas recusa toda a eminência de um sobre o outro" (Deleuze 9, p.24).

\section{Problema do paralelismo: as diferentes leituras}

A tradição interpretativa do paralelismo, comenta Chaui (6, p.704) foi desencadeada pelas indagações em torno da proposição EII, P7, transmitidas por Schuller na carta 63. Os comentadores passaram a discutir se o atributo pensamento teria uma amplitude maior que os outros atributos, observa Chaui (6, p.704), "porque sua potência seria tripla": em primeiro lugar, o atributo pensamento é uma potência de agir que produz ideias, em segundo lugar, o pensamento também produz as ideias dos modos de todos os outros atributo; em terceiro, é uma potência reflexiva, porque as mentes são capazes de pensar a si mesmas. Porém, Espinosa afirma no corolário dessa mesma proposição que a potência de pensar e a potência de agir de Deus são iguais e não que a potência do atributo pensamento excede a dos outros atributos.

Deleuze, em "Le parallélisme et l'immanence", observa que o termo paralelismo é próprio da filosofia de Leibniz, mas considera que este termo "designa adequadamente a filosofia de Espinosa" (Deleuze 10, p.95). De acordo com esta leitura, o paralelismo 
espinosano se apresenta em três fórmulas. A primeira remete para a "identidade de ordem ou correspondência entre os modos de atributos diferentes" (Deleuze 10, p.94). A identidade de ordem exige a "autonomia" das séries correspondentes dos modos, pois o pensamento não determina a extensão nem vice-versa. Contudo, não há apenas a mesma ordem, mas a mesma conexão entre as séries. A segunda fórmula exige, portanto, a "isonomia" de conexão ou "a igualdade de princípio entre séries autônomas" (idem 10, p.95), pois os modos dos atributos diferentes possuem a mesma realidade e potência, já que expressam a substância única. A terceira afirma a "identidade do ser": "os modos de atributos diferentes não possuem apenas a mesma ordem e a mesma conexão, mas o mesmo ser" (idem 10, p.96). É justamente por estabelecer a identidade do ser ou a "unidade ontológica" que Espinosa recusa a intervenção de um Deus transcendente, posto que a substância única opera como "causalidade imanente". O termo paralelismo é considerado adequado para compreender a teoria da expressão da substância única e imanente, mas Deleuze faz uma torção no sentido difundido pelos comentadores, pois enfatiza que não há nenhum privilégio do atributo pensamento sobre a extensão, nem da mente ou da razão sobre o corpo e as paixões.

Por seu estrito paralelismo, Espinosa recusa toda analogia, toda eminência, toda forma de superioridade de uma série sobre outra, toda ação ideal que suporia uma preeminência: não há mais a superioridade da alma/mente sobre o corpo nem do atributo pensamento sobre o atributo extensão. (Deleuze 10, p.96-7).

Chaui (1999) também sublinha que o termo "paralelismo" é inseparável da concepção leibniziana de expressão, porém é totalmente estranho à concepção espinosana. Enquanto Leibniz afirma a existência de relação entre infinitos modos heterogêneos e paralelos, para Espinosa, os modos diferentes são simultâneos e homogêneos, pois cada modo exprime a mesma natureza ou substância de seu atributo, ou seja, nenhum atributo ou modo exprime o outro.

Se a relação for uma relação entre heterogêneos, nada impede supor que sejam séries paralelas que se encontrarão no infinito; se, porém sabe-se que a expressão é uma relação entre homogêneos, que o exprimir não é o espelhar um outro e sim uma ação causal imanente de um princípio único internamente diferenciado, não há nem porque falar em 'paralelismo' (Chaui 6, p. 739).

Jaquet (2004), assim como Chaui, observa que o emprego do termo paralelismo ao pensamento de Espinosa traz mais problemas e complicações do que explica o sentido da união entre corpo e mente. A primeira comenta que Gueroult adota a tese do 
paralelismo em Espinosa, quando afirma que: "entre as duas ordens, trata-se mais de um paralelismo do que de uma identidade" (Gueroult, p.64 apud Jaquet 12). O termo paralelismo, porém, apesar de ser um termo de uso cômodo reduz, confunde e fornece uma compreensão falsa da questão da unidade e da mesma ordem e conexão, pois cria um esquema de justaposição de uma infinidade de linhas similares e concordantes, secantes ao infinito, introduzindo uma forma de dualismo e de pluralidade irredutível (Jaquet 12, p.11).

O corpo e a mente não são superpostos no ser humano enquanto paralelas, pois designam uma única e mesma coisa expressa de duas maneiras, segundo lemos no escólio da EII, P21: “a Mente e o Corpo, são um só e o mesmo indivíduo, o qual é concebido seja sob o atributo do Pensamento seja sob o da Extensão". Jaquet observa, com razão, que Espinosa emprega no corolário da EII, P7 o termo igualdade e não paralelismo. Além disso, o termo igualdade é empregado por Espinosa para comparar a potência de pensar da mente com a potência de agir do corpo na demonstração da EIII, P28: "Mas o esforço ou potência da Mente ao pensar é igual e por natureza simultâneo ao esforço ou potência do Corpo ao agir”. Portanto, a teoria da expressão em Espinosa é regida pelo princípio da igualdade e não pelo paralelismo, por isso, para a estudiosa, é mais importante investigar o que significa essa igualdade e afastar de vez essa noção exterior ao sistema de Espinosa (Jaquet 12, p.16). ${ }^{4}$

\section{Leitura de Chaui: Ética da Liberdade e da Felicidade}

Em A Nervura do Real, Chaui observa que a teoria da substância única como causa imanente e necessária e a teoria da mesma ordem e conexão entre as ideias e as coisas não podem ser confundidas com o privilégio do atributo pensamento, por isso recusa o emprego do termo "paralelismo". A autora examina também em outros textos sobre Espinosa o complexo contexto de produção da obra e as várias rupturas e inovações operadas pelo filósofo para fundamentar na Ética uma original filosofia da liberdade e da felicidade enquanto autodeterminação interna, estabelecendo as bases para uma nova filosofia da práxis. Não faremos um inventário de todas as rupturas e inovações apresentadas pela monumental análise conceitual de Chaui, destacaremos apenas algumas para compreender em que sentido a Ética implica uma nova concepção de filosofia prática ou da práxis. 
Primeira ruptura: Espinosa mantém a definição clássica de Aristóteles da ciência como conhecimento pela causa, mas rompe com a longa tradição aristotélica que concebe a ética como um conhecimento prático e não teórico. Chaui (3) destaca que para o aristotelismo o pathos é a voz da contingência, do acaso, não sendo possível uma ciência do que não seja causa necessária de si, do necessário. Aristóteles define a ação humana e seus derivados (os afetos, as paixões, a vontade, o pathos, em suma, todos os objeto da ética e da política) como fenômenos particulares e contingentes, pois envolvem a deliberação, a capacidade da livre escolha entre possíveis. Logo, os objetos da ética e da política não possuem uma causa natural, invariável e universal, e, por isso, diferem dos fenômenos da natureza, dos seres transcendentais e dos objetos matemáticos. Assim, na Metafísica, Aristóteles define a ética e a política como ciências da ação ou da práxis em distinção às ciências teóricas, que estudam as causas naturais e necessárias. 5

Em Laços do Desejo, Chaui demonstra a ruptura de Espinosa com a longa tradição moral aristotélica de mais de dois mil anos. Num primeiro movimento, o texto analisa a especificidade das concepções aristotélica e estoica de desejo, refletindo, em seguida, sobre a particularidade da concepção espinosana do desejo como conatus, cuja definição encontra-se na EIII, P7: “O esforço [conatus] pelo qual cada coisa se esforça para perseverar em seu ser não é nada além da essência atual da própria coisa”. A naturalização do desejo como conatus, isto é, potência natural e constitutiva dos corpos, permite desatar os laços, que, desde Aristóteles, prendiam o campo da ética ao da retórica. Espinosa marca a ruptura de sua Ética com a tradição retórica aristotélica, que considera o desejo e as paixões coisas antinaturais quando observa no Prefácio à Parte III que irá examinar tais objetos à luz do método geométrico, sinônimo de rigor científico:

agora quero retornar àqueles que preferem amaldiçoar ou ridicularizar os Afetos e ações humanos em vez de inteligi-los. Estes, sem dúvida, hão de admirar que eu me proponha a tratar dos vícios e inépcias dos homens à maneira Geométrica. (Espinosa 1, Prefácio, EIII).

Espinosa, assim como todos os filósofos modernos, naturaliza o desejo ou o conatus quando demonstra que os afetos e as paixões humanas são coisas naturais constitutivas dos corpos e produzidas pela causalidade natural e necessária. Contudo, somente o filósofo holandês não separa o campo da ética do campo das ciências da natureza, ao contrário, fundamenta nas Partes II e III uma ciência dos corpos em geral e do corpo humano em particular, uma ciência da mente e uma ciência dos afetos. Neste 
sentido, a Ética apresenta um novo modelo de filosofia da ação ao mesmo tempo prática e teórica, pois seu objeto (os afetos, as paixões, o desejo) são coisas necessárias e naturais, que podem ser demonstradas racionalmente pelo método geométrico.

\begin{abstract}
Assim como linhas, planos e corpo são efeitos necessários de movimento, também os afetos possuem causas determinadas que podem ser perfeitamente conhecidas. A dinâmica do conatus toma o movimento como uma causa, rigorosamente definida como tal, uma vez que é responsável pela gênese dos corpos e de seus efeitos, (...) permite uma ciência do desejo de estilo matemático, cujos pressupostos são: a causa do movimento é outro movimento; o começo de um movimento já é movimento; um corpo é feito de movimentos e causa de outros, e toda variação qualitativa - no caso, a variação afetiva causada pelo desejo - é uma variação de quantidades, velocidades e direções de movimento, ou, como exige Espinosa, de relações de proporção entre movimento e repouso. (Chaui 7, p.52).
\end{abstract}

Segunda ruptura: Chaui, no artigo "Ser Parte e Ter Parte: Servidão e Liberdade na Ética IV" (1993), examina a crítica espinosana à oposição entre liberdade e necessidade e nos dá outra pista para compreender a Ética como um novo modelo de filosofia da práxis, pois observa que "numa prodigiosa reviravolta da tradição éticometafísica, a filosofia espinosana demonstra que somos livres não apesar da necessidade, mas graças a ela e, ao contrário, que somos livres não graças à Fortuna, mas apesar dela" (idem 4, p.67). Em outras palavras: Chaui esclarece que o problema efetivo da Ética espinosana não é o do "determinismo" da necessidade natural versus a liberdade, tal como apresentam seus críticos, mas o problema da relação entre liberdade e Fortuna, ou seja, entre liberdade e contingência. Isto significa que é no campo da prática, isto é, da experiência necessária, natural e contingente, ou seja, no campo das paixões, ações e afetos experimentados por nossos corpos e mentes, que podemos produzir a liberdade e superar a servidão ou a impotência:

Expondo a vulnerabilidade extrema dos seres humanos e encontrando neles uma força peculiar que não pretende dominar nem controlar a Fortuna, mas vencê-la, expondo-a como fraqueza, ignorância e tristeza, a geometria da servidão deduz a virtude não como poderio intelectual sobre os afetos, mas como afeto mais forte do que as paixões, desnudando-as como naturais, necessárias, delírios e ilusões. (Chaui 4, p.67).

Chaui reitera que a Ética espinosana funda, a partir da teoria da causalidade única e natural, uma “ontologia do necessário" em contraposição à longa tradição teológico-metafísica, que "estabeleceu um conjunto de distinções com que pretendia determinar a distinção real entre liberdade e necessidade. Dizia ser por 'natureza' o que 
acontece 'por necessidade' e, ao contrário, 'por vontade' o que acontece por 'liberdade"' (Chaui 7, p.193). Espinosa contrapõe a ontologia do necessário à metafísica do possível e à teologia da contingência, pois sua ontologia expulsa o imaginário finalista e a noção de livre-arbítrio ou a escolha racional entre possíveis. Portanto, expulsa "o contingente e o possível, admitindo uma única distinção no interior da própria necessidade - o necessário pela essência e o necessário pela causa -" (CHAUI 7, p.197).

A análise da ontologia do necessário e da crítica espinosana da oposição entre liberdade e necessidade reforça a tese da Ética espinosana como modelo de filosofia simultaneamente teórica e prática, pois o conhecimento teórico de qualquer objeto, aparentemente possível e contingente, implica a demonstração da causa necessária e produtora de uma realidade determinada, da singularidade dos corpos, da prática ou da existência singular em ato. A teoria ou o pensamento racional não possui um privilégio em relação à experiência sensível ou afetiva, já que a expressividade da substância única parte do pressuposto da igualdade de potência e de realidade ou da mesma ordem e conexão entre os atributos pensamento e extensão.

Terceira ruptura: Uma das maiores inovações da Ética espinosana foi a ruptura com o dualismo substancial cartesiano. No lugar de duas substâncias, Espinosa demonstra que há apenas a substância única (Parte I). Na Parte III, a tese da mesma ordem e conexão é desdobrada em duas novas teses: a primeira afirma que há a mesma potência e mesma realidade entre a mente e o corpo; a segunda garante a autonomia entre os modos, que são regidos por leis próprias, por isso não pode haver uma determinação recíproca entre a mente e o corpo, como esclarece a proposição EIII, P2: "Nem o corpo pode determinar a mente a pensar, nem a mente determinar o corpo ao movimento e ao repouso".

Em outras palavras, esse conjunto de teorias que compõem a ontologia do necessário possibilita a Espinosa a recusar: $1^{\circ}$ ) as teorias da hierarquia da mente sobre $o$ corpo, que estabelecem o império da razão sobre as paixões; $2^{\circ}$ ) as teorias que defendiam que paixão e ação são termos recíprocos e intercambiáveis para explicar a vida afetiva. Como observa Chaui:

A tradição e o século XVII definem a paixão e a ação como termos reversíveis e recíprocos: a ação está referida ao termo de onde algo parte; a paixão, ao termo onde algo incide. 6 Eis por que se fala na paixão da alma como ação do corpo sobre ela e na passividade corporal como ação da vontade e da razão sobre ele. (...) Espinosa rompe radicalmente com essa concepção da vida passional. (...) Pela 
primeira vez, em toda história da filosofia, corpo e mente são ativos ou passivos juntos e por inteiro, em igualdade de condições e sem relação hierárquica entre eles. (Chaui 5, p.66).

Quarta ruptura: Chaui também destaca que a Ética espinosana rompe com outras duas tradições dominantes na história da filosofia moral: de um lado, com a tradição da "transcendência teológico-religiosa ameaçadora, fundada na ideia de culpa originária e na imagem de um Deus juiz"; de outro, "a da normatividade moral, fundada na heteronomia do agente, uma vez que este, para ser moralmente virtuoso, deve submeter-se a fins e valores externos não definidos por ele" (CHAUI 7, p.68). Enquanto a tradição teológico-religiosa parte da noção de livre-arbítrio para explicar porque o homem é um ser decaído, pois por sua culpa cometeu o pecado original e transgrediu os mandamentos divinos, a tradição normativa estabelece as normas morais a partir da imagem de coisas boas ou más em si, ou seja, apresenta o bom e o mau como modelos externos de conduta virtuosa e viciosa, além disso, identifica a liberdade com o poder da vontade racional para escolher entre os valores e as normas estabelecidos.

Espinosa demonstra que os principais conceitos da filosofia moral são preconceitos criados pela imaginação, tais como: $1^{\circ}$ ) o finalismo como lei divina e natural, pois, no Apêndice da Parte I7, ele observa que só há a causalidade natural, eficiente e imanente em ato; $2^{\circ}$ ) o livre arbítrio, pois demonstra que não existe uma vontade racional em si livre8, toda ação, desejo, vontade, pensamento e ideia são determinados pela causalidade natural e, portanto, é mera ficção ou crença definir a razão como um poder puro, autônomo e separado das determinações do seu corpo e dos outros corpos que o afetam; $3^{\circ}$ ) as noções de perfeição e imperfeição, de bom e mau, quando tomados como modelos para a ação e como coisas em si mesmas não passam de preconceitos que alimentam o medo e superstição, devem ser concebidos apenas como noções úteis. 9

\section{Considerações finais}

Com este breve inventário das rupturas e inovações operadas por Espinosa verificamos como Deleuze e Chaui demonstram que a Ética possui um caráter teórico indissociável de uma prática, tese que é obscurecida pelas leituras usuais do "paralelismo espinosano", que atribui um privilégio ao atributo pensamento. A compreensão da tese da mesma ordem e da mesma conexão entre as ideias as coisas 
possibilita compreender a radicalidade e originalidade dos conceitos e teorias da Ética espinosana, pois o conhecimento da causa adequada das coisas não visa à contemplação da determinação da causa natural, ao contrário, visa à transformação da experiência da impotência em potência de pensar e de agir. O próprio Espinosa esclarece o sentido do termo experiência no contexto de sua investigação, no escólio da proposição EII, P17: "visto que todos os postulados que assumi dificilmente contêm algo que não se constate pela experiência, da qual não nos é lícito duvidar depois que mostramos o Corpo humano existir tal como o sentimos (pelo col. EII, P13)".

Nestes termos, tanto a leitura de Deleuze quanto a de Chaui aponta para o estatuto prático e experimental da filosofia espinosana, sobretudo da Ética. Esta obra, além de reunir as principais teorias espinosanas, apresenta o método geométrico não apenas como um novo método teórico, que toma a matemática como ideal de rigor dedutivo, mas como um método experimental, pois permite a cada um experimentar a geometria e a ordem de perfeição da natureza na medida em que compreende a natureza e a geometria da potência e da impotência humana em sua experiência de vida singular.

Essa nova concepção de filosofia teórico-prática opera, portanto, como pensamento crítico e transformador, pois toma como objeto uma realidade concreta e determinada, no caso específico analisado, a experiência da vida afetiva dos indivíduos em sua singularidade em ato, ou seja, os modos de vida e de comportamento humanos. Ao retomar a leitura de Deleuze e de Chaui sobre a Ética espinosana sob a lente da filosofia prática ou da práxis objetivamos contribuir para o debate em torno do papel da ética na contemporaneidade a partir do deslocamento para o campo de uma ciência do comportamento tendo por referência a ciência espinosana dos afetos. Ainda temos muito a aprender com a reflexão de Espinosa, que no século XVII já propõe um novo modelo filosófico para pensar a ética fora do campo do moralismo maniqueísta, do finalismo moral, dos valores transcendentais, da superioridade da razão, da oposição entre liberdade e necessidade, da normatividade do dever.

Nem ética teleológica nem deontológica, as questões da liberdade, da servidão, das paixões e dos afetos são abordadas no âmbito da ciência espinosana dos afetos, no sentido clássico do termo, isto é, enquanto conhecimento demonstrativo e racional das causas reais que produzem determinados efeitos. No século XVII, o mecanicismo da causa eficiente é amplamente adotado como modelo de ciência para explicar os fenômenos da natureza, ou o reino da necessidade. Os pensadores modernos rompem com o modelo teleológico aristotélico-escolástico, que estabelece a hierarquia da causa 
final sobre a causa eficiente. Todavia, somente Espinosa recusa a noção da causa final para explicar o fundamento da ação humana e da liberdade como tem central da ética, pois para ele a noção de livre arbítrio é um dos piores preconceitos, que a ontologia do necessário visa desfazer (Cf. Apêndice EI).

Contudo, o modelo espinosano de filosofia-prática ou de ciência, que visa compreender a determinação da causa necessária, natural e eficiente de todo fenômeno, não foi o precursor do empirismo positivista, nem do determinismo da causa natural, tal como estabelecido pelo cientificismo a partir do século XIX. Em quase todos os manuais de filosofia e de ética encontra-se a tese do determinismo como uma das características centrais do pensamento de Espinosa. Esta leitura reducionista usa como argumentos as próprias críticas espinosanas à tradição, sem, no entanto, verificar a radicalidade das rupturas operadas pela Ética. Daí a importância do exame das leituras de Deleuze e de Chaui, que enfatizam várias teses que impossibilitam essa simplificação: a mesma ordem e conexão entre as ideias e as coisas garante não apenas a autonomia entre os fenômenos mentais e os fenômenos físicos ou corporais, mas assegura a igualdade de potência e de realidade. Portanto, impede tanto uma relação de hierarquia ou de império da mente sobre o corpo, ou da razão sobre a natureza, como pretendem os racionalistas, idealistas e intelectualistas, quanto à redução de todo princípio de causalidade à evidência empírica da causa natural, como pretendem os positivistas, materialistas e empiristas.

Caso não se compreenda o que significa em Espinosa: 1) recusar a oposição clássica entre liberdade e necessidade; 2) afirmar que a noção de livre arbítrio é uma ficção assim como as noções de causa final; 3) recusar a oposição entre bem e mal como se fossem coisas em si mesmas e valores transcendentes, que condenam e condicionam a vida imanente; 4) recusar a teoria da hierarquia da mente sobre o corpo, ou o império da razão sobre as paixões, ao mostrar que pensamento e matéria são atributos de mesma realidade e potência; 5) adotar o corpo, ou melhor, a relação corpo-mente como um novo modelo filosófico, como fio condutor para compreender a natureza e força dos afetos e a força da mente e da liberdade humana - em suma, caso não se compreendam as implicações e a profundidade de todas essas recusas sustentadas pelas originais teses teóricas da Ética -, não há como entender como esta filosofia prática ou da práxis aponta para uma filosofia da vida, da liberdade e da felicidade, a qual não pode ser reduzida a um determinismo naturalista, tampouco à autodeterminação do tipo intelectualista ou idealista. 


\section{DELEUZE AND CHAUI: \\ PARALLEL READINGS ON THE READINGS OF SPINOZA'S ETHICS}

Abstract: This article aims to examine how far the readings of Deleuze and Chaui help us understand the Ethics of Spinoza as an innovative practical philosophy or philosophy of praxis. The strong link between theory and practice has been weakened by many readings that support the thesis of the "spinoza's parallelism" as a privilege of the attribute of thought in relation to that of extension, this would imply a privilege of the theory to the practice and experience. The readings of Deleuze and Chaui instead emphasize that the originality of the theoretical principles of ethics lies in its necessary practical application , in other words in the inseparability of theory and practice, thought and extension, mind and body, types of knowledge and ways of life. Both propose another interpretation of nuclear thesis of parallelism in the philosophy of Spinoza. We are going to unfold this research in three topics: 1) reading Deleuze: Ethics as practical philosophy, 2) problem of parallelism: the different readings; 3) reading Chaui: Ethics as a philosophy of freedom.

Keywords: Spinoza. Ethics. Deleuze. Chaui. Parallelism. Practical Philosophy.

\section{REFERÊNCIAS BIBLIOGRÁFICAS}

1. ESPINOSA. B. Ética. Tradução do Grupo de Estudos Espinosanos GEE-USP. São Paulo: Edusp, 2013 (no prelo).

2. CHAUI, M. "Sobre o Medo". In Os sentidos da Paixão. Org. Adauto Novaes. São Paulo: Cia das Letras, 1987.

3. "Laços do desejo". In O Desejo. Org. Adauto Novaes. São Paulo: Cia das Letras, 1990.

4. . "Ser Parte e Ter Parte: Servidão e Liberdade na Ética IV". In Discurso, São Paulo, nº 22, p.63-122, 1993.

5. . Espinosa uma filosofia da liberdade. São Paulo: Moderna, 1995.

6. . A Nervura do Real. São Paulo: Cia das Letras, 1999.

7. . Desejo, Paixão e Ação na Ética de Espinosa. São Paulo: Cia das Letras, 2011.

8.DELEUZE. G. Spinoza: Philosophie Pratique. Paris: Minuit, 1981. 9. Espinosa e a Filosofia Prática. Tradução de Daniel Lins e Fabien

Pascal Lins. São Paulo: Escuta, 2002a.

10. . Spinoza et le problème de l'expression. Paris: Minuit, 2002b.

11. . Nietzsche et La Philosophie. Paris: PUF, 1988.

12. JAQUET. C. L'unité du corps et de I'esprit: affects, actions et passions chez Spinoza. Paris, P.U.F., 2004. 


\section{NOTAS}

1 Usamos para as citações a tradução de Daniel Lins e Fabien Pascal Lins do livro Deleuze: Espinosa e a Filosofia Prática. Tradução. São Paulo: Escuta, 2002.

2 Desenvolvemos esta hipótese de leitura na comunicação "Deleuze: a filosofia prática de Espinosa enquanto ciência do comportamento"apresentada no XV Encontro Nacional da ANPOF, Curitiba, 2012 (artigo no prelo).

3 Para as citações da Ética adotamos a tradução do Grupo de Estudos Espinosanos GEE-USP (no prelo Edusp), com a seguinte notação: EI, EII, EIII, EIV, EV, para marcar a Parte do livro, seguido da proposição $(\mathrm{P})$ e do número.

4 Cf. Jaquet (12), seção Pour en finir avec le parallélisme, na qual a autora apresenta os argumentos contrários a tese do paralelismo aplicada ao pensamento de Espinosa.

5 Na Metafísica, Livro E, 1025b, Aristóteles define os três grandes tipos de ciência: 1. a ciência metafísica, cujo objeto é o Ser em suas formas separada da matéria; 2 . as ciências teóricas, que inclui as ciências da natureza, cujo objeto são as causas necessárias do movimento, da substância e da essência dos seres naturais, e, as ciências matemáticas, cujo objeto são os seres abstratos, não-físicos e imóveis (os números e suas propriedades etc.); 3 . as ciências práticas ou da praxis: a ética e a política, estudam os objetos que dependem das ações humanas, ou seja, a finalidade da ação moral e da ação política, que é contingente, que permite a escolha da vontade racional entre possíveis. Enquanto, os dois primeiros grupos de ciências estudam objetos universais e suas causas necessárias, isto é, invariáveis; as ciências da ação estudam o possível, que é variável, por isso não podem ser consideradas nem ciências teóricas nem ciências que estudam causas naturais e necessárias.

6 Descartes observa: "Ora, sempre julguei que é uma e mesma coisa que é denominada ação quando a relacionamos ao termo de onde ela procede e paixão com respeito ao termo no qual ela é recebida" (Carta a Hyperaspistes, agosto de 1641).

7 "Por outro lado, não é preciso muito trabalho para que agora eu mostre a natureza não ter para si nenhum fim prefixado e todas as causas finais não serem senão humanas forjaduras.”( Espinosa 1, Apêndice EI).

8 "Daí segue, primeiro, que os homens conjecturam serem livres porquanto são conscientes de suas volições e de seu apetite e nem por sonho cogitam das causas que os dispõem a apetecer e querer, pois delas são ignorantes". (Espinosa 1, Apêndice EI).

9 "Em seguida, mostrarei sua falsidade e, enfim, como dele se originam os preconceitos sobre bem e mal, mérito e pecado, louvor e vitupério, ordem e confusão, beleza e feiúra, e outros desse gênero". (Espinosa 1, Apêndice EI). 